\title{
SYNTHESIS OF SCHIFF BASE VERDANTIOL BY SIMPLE CONDENSATION
}

\author{
Niken Oktaviani $^{a}$, Leny Heliawati $^{a}$, Yudhie Suchyadi ${ }^{\left.a^{*}\right)}$ \\ ${ }^{a)}$ Universitas Pakuan, Bogor, Indonesia \\ ${ }^{*}$ Corresponding Author: yudhie@unpak.ac.id
}

Article history: received 29 July 2019; revised 29 July 2019; accepted 25 August 2019

\begin{abstract}
Abstrak. Schiff base is a chemical compound that is formed from the reaction between aldehydes and primary amines by condensation and produces by-products in the form of water. Schiff base is the raw material that is added in making Fragrance. The purpose of this study was to determine the method of synthesis of Schiff base verdantiol with simple condensation. The research method was carried out with four stages: preparation, synthesis, testing and measurement of parameters, and calculations. Preparation includes weighing the raw material Schiff base verdantiol. Schiff base synthesis is carried out by stirring at a temperature of about $90^{\circ} \mathrm{C} \pm 5^{\circ} \mathrm{C}$ (Arctender, 1969) with a modification time of 15 minutes, 30 minutes, 1 hour, 2 hours and 3 hours. Testing and measurement parameters include organoleptic, density and specific gravity tests in pycnometer and compound confirmation using Gas Chromatography Mass Spectrometry. The results showed that the optimum synthesis of Schiff base verdantiol compounds was carried out at a heating time of 2 hours. The results of odor, color, density and gravity specifications heating time 2 hours according to specifications with the standard. GCMS confirmation results at 2 hours percent similarity are above $94 \%$.
\end{abstract}

Keywords: schiff base; verdantiol; condensation

\section{INTRODUCTION}

The industry is a human endeavor so that goods obtained from nature can be utilized as products that have sale value and have a profitable profit in economic terms. Material from nature has chemicals that can be used for certain purposes, such as food, fuel, fuel, fertilizer, cosmetics, etc. so that human life becomes more comfortable. A chemical industry must pay attention to environmental sustainability and is expected to process materials that are safe for the environment, as well as products produced that are environmentally friendly [1]. Perfume seeds or fragrance seeds are genuine fragrance oils or extract oils from fragrances that are still pure and have not been mixed with alcohol or other chemical liquids. The smell of these fragrance seeds is very strong and stinging in shape like oil, so it is very rarely used directly. (Hardjono [2]).

A fragrance is not a single material of clearly defined properties, but rather a mixture ofindividual chemicals, each behaving according to its own unique attributes. Characterizing these chemicals separately, and then combining their effects, allows the behaviorof the complete fragrance composition in diverse media to be understood. Importantproperties of fragrance chemicals include volatility, polarity, surface activity and stability.Each fragrance component interacts with the chemical and structural nature of theenvironment to determine the aesthetic and the physical characters of the final system. The combined talents of the perfumer and the technical staff, working closely together,are needed to create a successful commercial product [3].

Three main methods are used to concentrate plant flavor and fragrance substances:1. distillation2. mechanical separation ("pressing")3. solvent extractionThe qualitative and quantitative composition, and thus the sensory properties, of theproduct depend on the isolation procedure [4]. Making Fragrance is very dependent on the characteristics and interactions of the raw materials added. One of the ingredients added is the Schiff base. Schiff base is a chemical compound that is formed from the reaction between aldehydes and primary amines by condensation and produce a by-product in the form of water. Condensation is the process of releasing heat from a system that causes vapor to turn into liquid. Schiff base which is often used in making fragrance is Bucinal-methyl anthranilate or better known as Verdantiol. Because Schiff base verdantiol is often used in the fragrance industry but the price is quite high, research on the synthesis of optimum base verdantiol Schiff by simple condensation using raw materials of Methyl anthranilate as an amine and Lillyal as an aldehyde. This research was conducted to determine the optimum time of synthesis of Verdantiol Schiff base so that it is expected to be a reference source for further research on the synthesis of Schiff base as a raw material for fragrance and the benefits for the fragrance industry in reducing production costs.

\section{RESEARCH METHODS}

The experimental method consists of four stages: preparation, synthesis, testing and measurement of parameters, and calculations. Preparation involves weighing the raw material of Schiff base verdantiol in the form of Methyl Anthranilate and Lillyal according to the theoretical comparison of molecular weights. Schiff base synthesis is carried out by stirring at a temperature of about $90^{\circ} \mathrm{C} \pm 5^{\circ}$ 
C (Arctender, 1969) with a modification of time for 15 minutes, 30 minutes, 1 hour and 2 hours. Organoleptic test in the form of color and odor observations with flavor \& texture profile test methods. Measurement of density and specific gravity in picnometry using pycnometer, as well as for confirmation of compounds by Gas Chromatography Mass Spectrophotometry [5]

\section{RESULTS AND DISCUSSION}

The preliminary analysis aims to find the optimal stirring time with the color change [6]. Preliminary analysis results found that the optimal stirring occurred for 10 minutes and the optimal synthesis of verdantiol is accompanied by heating. One of the physical tests tested was an odor, the test was carried out by six trained panelists. In the organoleptic test results it was found that the odor that was in accordance with the standards was at 1,2, and 3 hours. The color test is a physical test which is an important parameter for the optimum formation of a Schiff base verdantiol [7].

Testing the product density made at 2 hours and 3 hours of heating results in an average density of 1,050 g / $\mathrm{mL}$ and $1,052 \mathrm{~g} / \mathrm{mL}$, respectively. The two mean density values are included in the standard range of verdantiol density [8], which is 1.050 - 1.058. The product-specific gravity test made at 2 hours and 3 hours heating time produces an average specific gravity value of 1.052 and 1.054, respectively. The two mean values of specific gravity are included in the standard range of specific gravity verdantiol, which are $1.050-1.058$.

Schiff base verdantiol test results in GCMS products, obtained two data, namely chromatogram derived from gas chromatography analysis followed by reading on the mass spectra. Gas chromatography analysis based on the boiling point and molecular weight of compounds [9]. The boiling point and lower molecular weight of the compound will come out as the initial peak.

From the product chromatogram produced, it is known that several components are the target compound (C), namely verdantiol, as the main component. In addition, it also identified the presence of compound A (methyl anthranilate) and compound B (Lillyal) which is the raw material for making Schiff base verdantiol.

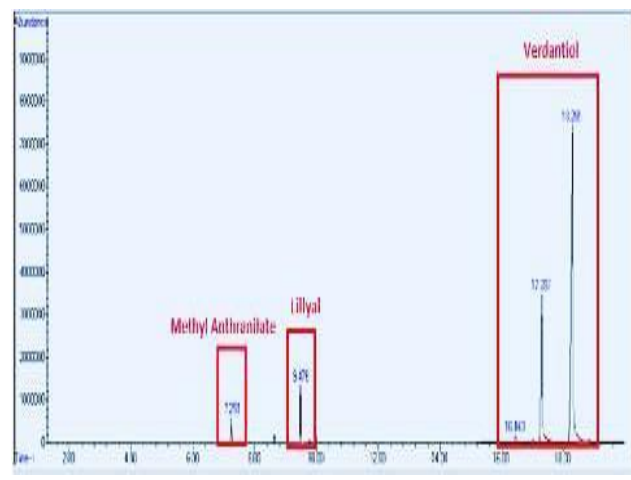

Figure 1. Verdantiol D1 Chromatogram

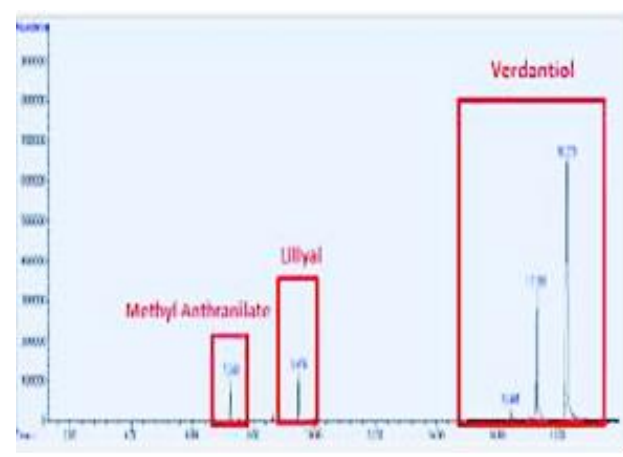

Figure 2. Standard Chromatogram of Verdantiol Compounds

Retention time (RT) data and \% similarity of a sample with verdantiol standard can be confirmed that the base of verdantiol Schiff has been formed, although it is not fully formed. This is proven by the data above that the Verdantiol Schiff base has formed a retention time (RT) of 16-18 minutes, but methyl anthranilate RT 7,251 and Lilly RT 9,476 are still found as verdantiol raw material. Formation of verdantiol Schiff base is still ongoing even in conditions of room temperature, the longer the storage time of the Schiff base the more the Schiff base is formed. According to Schmidt (2002) a Schiff base is difficult to analyze using gas chromatography because the Schiff base has a large molecular weight and boiling point, so the characterization or test parameters are only on specific odor, color, and gravity. That is why\% area is not used as company specifications and is only used for compound confirmation.

Percent (\%) area of verdantiol, lillyal and methyl anthranilate in a variation of heating 15 minutes, 30 minutes, 1 hour, 2 hours and 3 hours continues to change. When the heating time is 15 minutes\% the verdantiol area is around $83-85 \%$ while for the variation of time 30 minutes- 3 hours there is an increase in the value of the $\%$ area around $90-92 \%$. This is because the amount of verdantiol that is formed is increasing. All data is the result of the analysis obtained from Library Wiley with a similarity percentage above $94 \%$.

\section{CONCLUSION}

The conclusions obtained from this study are: The optimum Schiff base verdantiol compound can be synthesized by simple condensation at $90^{\circ} \mathrm{C} \pm 5^{\circ} \mathrm{C}$ with stirring for 2 hours.

\section{REFERENSI}

[1] P. Citroreksoko, A. Taufik, A. Murharini, S. Purawisastra, and Y. Suchyadi, Kimia Terapan, 1st ed. Jakarta: Universitas Terbuka, 2012.

[2] Hardjono, S., 2004, Kimia Minyak atsiri, 
Gadjah Mada University Press, Yogyakarta, hal 2, 9-15.

[3] Rowe, D., Stephen J. Herman 2005. Chemistry and Technology of Flavors and Fragrances. Blackwell Publishing Ltd. British.

[4] Surburg, Horst, and Panten, Johannes. 2006. Common Fragranceand Flavor Materials. WILEYVCHVerlagGmbH\&Co.KGaA,Weinheim

[5] Pavia, et al,. 2001. Introduction Of Spectroscopy. Departmen of Chemistry Western Washington University. Washington.

[6] Choew, et al,. 2003. Antioxidant Activity and Safety of 50\% Ethanoic Red Been Extract (Phaceolus raditus L, Var aurea). Journal of Food Science

[7) Salazar, M. E. Pozos, P. Cordero, J. Perez, M. C. Salinas, and N. Waksman. 2009. Determination of the antioxidant activityof plants from northeast Mexico. Pharmaceutical Biology, vol.46.

[8] L. Heliawati, Y. Suchyadi, and A. Iryani, Kimia Organik 1, 01 ed. Bogor: LPPM Universitas Pakuan, 2016.

[9] L. Heliawati, Y. Suchyadi, and A. Iryani, Kimia Organik 2, 01 ed. Bogor: LPPM Universitas Pakuan, 2018. 